\title{
Integration of optics into the undergraduate physics curriculum at Millersville University
}

\section{Natalia Dushkina}

Natalia M. Dushkina, "Integration of optics into the undergraduate physics curriculum at Millersville University," Proc. SPIE 9665, Tenth International Topical Meeting on Education and Training in Optics and Photonics, 96651 J (3 June 2007); doi: 10.1117/12.2207327

SPIE Event: Tenth International Topical Meeting on Education and Training in Optics and Photonics, 2007, Ottawa, Ontario, Canada 


\title{
Integration of Optics into the Undergraduate Physics Curriculum at Millersville University
}

\author{
Natalia M. Dushkina \\ Department of Physics, Millersville University, P.O. Box 1002, Millersville, PA 17551-0302 \\ Tel: (717) 872-3424; Fax: (717) 872-3985, E-mail: Natalia.Dushkina@millersville.edu
}

\begin{abstract}
A discovery based lab course in applied optics was developed and will be offered for the first time at Millersville University (MU) in the fall of 2007. The course will deal with fundamental optics and optical techniques in greater depth so that the student is abreast of the activities in the forefront of the field. The goal of the course is to provide hands-on experience and in-depth preparation of our students for graduate programs in optics or as a workforce for new emerging high-tech local industries. The new 300 level course will be required for BS physics majors, but will be open also to the full spectrum of science majors, who have the appropriate background. The optics course consists of four contact hours per week including a one-hour lecture and a three-hour lab. Students will learn applied optics through sequence of discovery based laboratory experiences. The guided but open-ended approach provides excellent practice for the academic model of science research. The lab experiments are chosen from a broad range of topics in optics and lasers, as the emphasis is on geometrical optics, geometrical aberrations in optical systems, wave optics, microscopy, spectroscopy, polarization, birefringence, laser generation, laser properties and applications, and optical standards. The starting budget of about $\$ 60,000$ provided state-of-the-art lab equipment from Newport Co. and MICOS Co. The attraction of the course is shown by the active registration among physics, chemistry and biology majors.
\end{abstract}

Keywords: optics, laboratory course, optics education

\section{Introduction}

The purpose of this paper is to describe the rationale for the development of a new course and educational materials in optics at Millersville University, PA. We have studied carefully the experience of the optics programs at New Jersey Institute of Technology (NJIT) [1]-[2], North Dakota State University (NDSU) [3] and Indiana University of Pennsylvania (IUP) [4]. The optics course will provide the basic resources for both research and training in modern optics. It will promote learning, teaching and training of students, faculty and K-12 teachers. A budget of $\$ 60,000$ was allocated and already used to cover the initial equipment costs. Our optics course implements commercially available kits from Newport Co. and MICOS Co. The course goals, objectives, content, equipment, and assessment methods are discussed in the paper. Our long term goal is a new option for a BA degree in physics with optics, which the department will be able to offer in the future after the implementation of another advanced optics courses.

\section{1 Who are we?}

Millersville University (MU) is one of the 14 universities within the Pennsylvania State System for Higher Education (PSSHE). Founded in service to a rural nineteenth century Lancaster Pennsylvania, twenty-first century Millersville University is a vibrant public liberal arts university in a vital economic region. MU promotes intellectual development through a comprehensive range of meritorious baccalaureate and master programs offered to more than seven thousands undergraduates and about a thousand graduate students. Millersville has earned its place among US News \& World Report's top public universities in the North and is recognized for its academic excellence in Martin Nemko's book, "How to Get an Ivy League Education at a State University." [5]

Tenth International Topical Meeting on Education and Training in Optics and Photonics, edited by Marc Nantel, Proc. of SPIE Vol. 9665, 96651 · • (c) 2007 SPIE, OSA, IEEE, ICO doi: $10.1117 / 12.2207327$ 
All resources, time, funding, and energy of the MU Physics Department are focused on doing one thing extremely well: Undergraduate Physics. We challenge thoughtful students, providing the opportunity and incentive for all to achieve their fullest. The Department offers high-quality four-year undergraduate degrees of BS and BA in Physics (option in computer science, meteorology, nanotechnology, philosophy and polymer science), and BS in Education, as well as two co-operative programs. The first is a 3/2 Program - three semesters at MU and two at Pennsylvania State University (PSU) or University of Southern California, after which students get two degrees, BA in Physics and BS in Engineering. The BA with Nanotechnology option is also a co-operative program with Penn State. A student takes the basic physics courses of a B.A. degree at Millersville, and after spending a semester at the Penn State Nanofabrication Facility learning the specialized techniques of nanotechnology, receives a BA degree from Millersville in Physics with a Nanotechnology Option. The second co-operative program is a 4/2 Program with PSU which offers BS in Physics and MS in Engineering degrees. The department of physics is one of seven departments in the School of Science and Mathematics and consists of seven full time faculty and one permanent part time faculty. At any time we have 60 to 100 physics majors. On the average, nine students graduate every year from our department. We have low student/faculty ratio (15/1) and all labs are taught by Ph.D. faculty using hands-on experiments and not simulations. Many upper level elective courses in Physics have 5-15 students. Because we do not have a graduate degree program, advanced projects are integrated into the curriculum and are focused on the undergraduate student. In 2001 the department moved into new facilities in a new building and older facilities were then renovated. This expansion of space and resources has been extensively developed over the last five years and provided the base for expansion of new programs and research ideas.

Millersville is conveniently located in the heart of Susquehanna Valley, almost equally distant from Philadelphia, Baltimore and Washington DC, and at about three hours drive from New Jersey and New York, an area of abundant advanced research centers and high-tech industries providing more opportunities for employment and graduate studies while keeping vital the connections to the local community. The driving distances to Pittsburg, State College and Rochester facilitate the contacts with the Northpointe Technology Center in Freeport (33 miles from Pittsburg), Penn State Technology Park and The Institute of Optics, University of Rochester.

\subsection{Rationale}

Optics, the study and manipulation of visible light, has always been an important sub-discipline in physics, and clearly, it will contribute to the most important technologies of the $21^{\text {st }}$ century. Optical devices and laser applications are already an inherent part of our daily life. In recent decades, the use of optics has transcended the traditional devices such as cameras, microscopes, and binoculars and has merged with atomic physics and nanotechnology. The development of the laser and the use of optical cable for communication initiated a new technological revolution. The euphoria for internet connectivity and the huge amount of information upload daily via the internet impose rapidly rising demands for higher bandwidth and faster speed which drives the incessant growth and development of fiber optic communications [6]. Every single student in my class has a cell phone and a CD player, but few know what an optical fiber is and how a laser works.

Understanding the nature of light, its propagation and interaction with matter is essential to physics and hands-on experiences greatly enhance that understanding. Currently there are no courses at MU dedicated to optics at any level, although optics is woven into some courses and laboratories such algebra and calculus based PHYS 132 or 232. The five-year department review report, as well as feedback from alumni, showed a gap in the department curriculum in the area of applied physics, and more specifically in optics.

Recognizing this gap, the Physics Department has taken steps over the past five years to expand its undergraduate physics curriculum and to increase our expertise in this important sub-discipline. Two experimentalists, a specialist in experimental optics and a specialist in solid state physics whose expertise includes optics, have been recently hired. Their presence at the department resulted in an increased number of undergraduate research projects in optics: measuring the speed of light in water, observation of surface plasmon resonance effect in thin silver and gold films, applications of laser pointers in the secondary physics education, measuring the light momentum, holography in thin films of silver halogenide and holographic recording in lithium-neobate crystal [7]. All this led naturally to the development of a new rigorous lab-based optics course, which will be offered for the first time at MU in fall 2007 and will be required for BS physics majors. More recently the Dean of the School of Mathematics and Science released substantial funds to the development of the new course. The current budget of about $\$ 60,000$ secured the state-of-the-art laboratory equipment for this course. The equipment will also be used by physics students and faculty for their research in the field of optics, 
as well as to evoke an interest in top high school students in optics and science carriers. With an addition of another advanced optics course in future, the Department will be able to offer a new option in BA physics with optics.

\subsection{Outreach}

Because of the mathematics involved and presumptions that physics is a difficult science, most high school students receive little exposure to physics, and, consequently, to optics. As a result, few students are aware of the ample career opportunities in this field. In order to attract the student's attention to this rapidly evolving discipline, I offer annual summer workshops for high school students. The first, Color Formation, is addressed to 8-9 graders (usually students with no exposure to physics), while the second one Physical Colors targets the junior and senior students (10-12 graders) who may have had taken physics courses. These two workshops are part of the educational and research activities of the Summer Science Training Program (SSTP) held for three weeks on the MU campus for a select group of local and regional high school students. The new optics course will give new opportunities to enrich the existing workshops and to expand our offerings with a workshop suitable for high school physics teachers.

Another way to promote participation of bright students in optical programs is mentoring high school student research projects. I sustain a continuous collaboration with Jim Ringlein, a physics teacher at the Lancaster Country Day School supervising his student's projects in optics and helping them to build optical experiments. I introduced the phenomena of surface plasmon resonance (SPR) to him and to one of his students and opened my lab for them to study SPR in porous gold samples [8].

Millersville University has the most successful science programs of any school within the PSSHE system. The Physics Department, in particular, has generated over the last ten years many more Baccalaureate degrees than any other PSSHE University. However, we cannot be complacent. Technologies and their societal relevance change and we must adapt with them. This optics course will be an important component in maintaining the currency of our programs and retaining our ascendant position within the PSSHE system.

\section{The newOptics course at MU}

\subsection{Objectives}

The main objective of the new lab-based optics course is to provide physics majors and other science students with hands-on experience and in-depth preparation for graduate programs in Optics, Optoelectronics, Optical Engineering, or as a workforce for new emerging high-tech local industries, via broader and deeper knowledge of basic concepts and principles of optics and optical techniques. The goal is to provide a clear understanding of the fundamentals, and to provide hands-on experiences which greatly enhance understanding of the nature of light, its propagation and interaction with matter. The course will introduce the science majors to basic optical systems and techniques in greater depth so that the student is abreast of the activities in the forefront of the field. Students will be required to participate in a multidisciplinary project, complete a report and give a PowerPoint ${ }^{\circledR}$ presentation in class.

\subsection{Course description}

The new optics course will be 300-level of two credit hours and will be taken by students typically in their fifth semester. This course is required for BS physics majors, but will be open also to chemistry, biology, earth science, computer science and other majors, who have met the prerequisite requirements MATH 211: Calculus 2 and university physics PHYS 232 or PHYS 132. This optics course will be very useful for chemistry majors since it provides basic knowledge of optics associated with the analytical part of chemistry. It will be beneficial also for computer science majors, since knowledge of modern optics is essential for fiber optics communication and data storage. Microscopes and lasers are widely used also in biological experiments. The MU Biology Department has a well-equipped microscopy center, including an Atomic Force Microscope (AFM), which is actively used by students and faculties for undergraduate research. Therefore, biology majors will be encouraged to gain knowledge in optics before they handle sophisticated instruments in this center.

The course enrollment is restricted only by prerequisites and lab equipment limitations. The initial budget ensured the equipment for four lab stations. The Department has provided a large laboratory room dedicated 
only to this course. Since there are only four lab stations in this room, there is plenty of space for the students to perform the laboratory experiments. Considering two or three students per station, the maximum enrollment in the course at this moment is limited to 12 students.

The optics course is designed for juniors and seniors whose background is one year of university physics and two years of calculus and differential equations. To facilitate their transition to the challenges of the new course, we will put some review materials on the department website. The highest priority of our optics course is creative and critical thinking, and life-long learning. This determines our teaching strategies. We emphasize concept development and qualitative and quantitative analysis. Demonstrations, thought experiments, guided class and group discussions, especially about misconceptions concerning optics, case studies, and peer-guided problem solving are part of our interactive learning strategies. Students will learn and experience applied optics through sequence of open-ended laboratory experiments and multidisciplinary projects. In order to enhance interactive learning and deeper understanding of the most important concepts and phenomena of optics, the laboratory exercises are designed as hands-on use of state-of-the-art equipment. This guided but open-ended approach provides excellent practice for the academic model of science research. The lab experiments are chosen from a broad range of topics in optics and lasers, as the emphasis is on geometrical optics, wave optics, microscopy, spectroscopy, polarization, birefringence, and properties of lasers. Both, the lab and lecture portions of the course are taught by PhDs in optics and physics faculties.

The optics course consists of one-hour lecture and a three-hour lab. The laboratory portion is the critical and most important part of the course, since it provides the tools and experience that students can take back to their respective disciplines and projects. The laboratory part uses the discovery based approach in which students have to investigate a hypothesis by designing and realizing the experiments, predicting relations and results, and processing the data. Therefore, no laboratory experiment write-ups will be handed out, but students will have access to the devices and optical kit manuals. Additional materials over the Web may be also used.

Since the new course will be open to different science majors, we envisage multidisciplinary projects which will enable them to successfully apply optics in their respective majors. Bearing in mind the experience of the Optics Program of North Dakota State University, the projects will be offered in the beginning of the course to provide an early start and enough time for accomplishment. The projects will be determined on the base of the student's interests and background, current undergraduate research projects they are working on, prospective plans for graduate studies or eventual job placement. Some example of such projects might be optical properties of thin semiconductor films or sculptured thin films, diffraction from thin films of selfassembled micron size particles, image processing, fiber optics, diffraction effect from butterfly wings, digital holography, ocean optics, etc. Presentations can include theoretical background, life demonstrations, simulations, and experimental results.

\subsection{Course content}

The general physics courses encompass some concepts of electromagnetic waves and propagation of light: reflection, refraction, and total internal reflection, image formation with lenses and mirrors, fibers, dispersion, interference, diffraction, polarization, atmospheric phenomena, human eye, color mixing, shadows, eclipses. But all these basic optical phenomena are described usually in two chapters, sometimes just a paragraph for a topic with broad applications. The new optics course will enrich and broaden this background with knowledge about aberrations of optical systems, microscopes and telescopes, cameras and photography, visual processing, light sources and detectors, quantum nature of light, lasers, laser applications, holography, birefringence, thin films and optical coatings, nonlinear optical phenomena, ocean optics, ultraviolet (UV) and infrared (IR) optics materials. Part of the lecture material will be covered in the laboratory using just-in-time teaching method. Students from different science majors will work on optics projects related to their discipline and will have to make a PowerPoint ${ }^{\circledR}$ presentation to the entire class. Besides background learning on their own, this should cover various topics that would not normally be included in the course.

The lecture portion of the course will follow the main topics in the E. Hecht, Optics, $4^{\text {th }}$ ed., Addison Wesley, 2002. But other classical texts will be also recommended to the students and will be possibly in use [9][13]. Course materials will be available to students also through the university's Blackboard website. There is rich information posted on the websites of NJIT and NDSU which will be also referred to students. This, in addition, will introduce our students to the facilities and curricula of these leading Optics programs. 
We plan fourteen separate experiments completed in three-hour blocks. The lab portion of the course will start with an introduction to the safety standards of using optical and laser sources and systems. The basic equipment for most of the experiments is The Projects in Optics Kit of Newport Corp. This is a set of laboratory equipment containing all of the optics and optomechanical components needed to complete a series of experiments that will provide students with basic background in optics and practical hands-on experience in laboratory techniques. The kit comes with a very well written workbook [14], which will serve as the main supplement to lectures and will be available to students as a source of information for the lab projects. For the last experiment, an investigation of the Helium-Neon (He-Ne) laser cavity, students will be challenged to build a He-Ne laser using the state-of-the-art MICOS' He-Ne laser kit. We are aware that the lab experiments and individual projects will be challenging and will require careful guidance to secure the successful student's performance and data interpretations. We rely on the previous experiences of the science majors with our PHYS 232 general physics course which uses the peer-reviewed discovery based approach in the physics lab.

Table 1: PHYS 331 Optics Laboratory

\begin{tabular}{|c|c|c|}
\hline & Eab projects & स्डcटांगांणn \\
\hline 1 & $\begin{array}{l}\text { The laws of geometrical optics; } \\
\text { Image formation }\end{array}$ & $\begin{array}{l}\text { This will be an introductory lab which will make the transition to the } \\
\text { new course via summarizing the student's previous experiences in } \\
\text { optics from the general courses in physics and will introduce students } \\
\text { to more complicated optical systems. Students get familiar with safety }\end{array}$ \\
\hline 2 & Geometrical aberrations & $\begin{array}{l}\text { standards. } \\
\text { Telescopes and binoculars, correction of aberrations, photodetectors }\end{array}$ \\
\hline & & and computer data acquisition with Vernier SoftwarelLogger Pro 3. \\
\hline 3 & Microscopy & Optical microscope, magnification and resolution limits, electron \\
\hline 4 & Reflection and Refraction & $\begin{array}{l}\text { microscope, Atomic Force Microscope (AFM) } \\
\text { Prisms: Dove prism, roof prism, retro-reflectors; total internal } \\
\text { reflection; attenuated total internal reflection; surface plasmon }\end{array}$ \\
\hline 5 & Expanding laser beams & $\begin{array}{l}\text { resonance in silver films, waveguides and optical fibers. } \\
\text { The experiment demonstrates the design of two types of laser beam } \\
\text { expanders - the Galilean and the Keplerian. Students gain experience }\end{array}$ \\
\hline 6 & Diffraction of circular apertures & $\begin{array}{l}\text { Fresnel and Fraunhofer diffraction. Students measure the diffraction } \\
\text { effects of circular apertures and experience how the size of the aperture }\end{array}$ \\
\hline 7 & $\begin{array}{l}\text { Single slit diffraction and } \\
\text { double slit interference }\end{array}$ & $\begin{array}{l}\text { determines the resolving power of alt opticat instruments. } \\
\text { Using a single "infinitely" tall slit, students witness the diffraction } \\
\text { which takes place in direction perpendicular to the small dimension } \\
\text { and investigate the interference pattern of two nearby slits, and }\end{array}$ \\
\hline 8 & The Michelson interferometer & $\begin{array}{l}\text { diffraction grating properties. } \\
\text { Students build a Michelson interferometer and use it as a means to }\end{array}$ \\
\hline 9 & Interference of light & $\begin{array}{l}\text { Newton's rings, thin-film interference. Students will use the same } \\
\text { arrangement as in lab } 8 \text { to test optical components in monochromatic }\end{array}$ \\
\hline 10 & Lasers and coherence & $\begin{array}{l}\text { lightt (Twyman-Green interferometer). } \\
\text { Students examine the frequency separation between the axial modes of }\end{array}$ \\
\hline 11 & Polarization of light & $\begin{array}{l}\text { a He-Ne laser with Michelson interferometer. } \\
\text { The students use a He-Ne laser with three modes (two of the modes } \\
\text { polarized orthogonally to the third mode) to get experience in the } \\
\text { orientation and generation of polarized light, as well as mode }\end{array}$ \\
\hline 12 & Birefringence of materials & $\begin{array}{l}\text { Sweeping. } \\
\text { Students become familiar with uniaxial crystals, the extraordinary } \\
\text { index of refraction and quarter-wave plates by using birefringence of a } \\
\text { material to change polarization of light; students build an optical }\end{array}$ \\
\hline 13 & The Abbe theory of imagining & $\begin{array}{l}\text { isolator and polarization rotator. } \\
\text { Students investigate the spatial frequency content of objects and how }\end{array}$ \\
\hline 14 & He-Ne Laser Cavity & $\begin{array}{l}\text { Students use MICOS' state-of-the-art laser education kit to get familiar } \\
\text { with optical cavity (confocal cavity, near concentric cavity), to build a } \\
\text { He-Ne laser and to optimize its properties (intensity distribution, }\end{array}$ \\
\hline
\end{tabular}




\section{4 Course budget}

The funds for the new course in Optics were provided solely by the Dean of the School of Science and Mathematics at MU. The total cost of equipment was constrained to be within $\$ 58,212$. The limited budget required a cost-saving and cost-comparison approach when planning and buying the state-of-the-art equipment needed for the optics laboratory. The NJIT approach of computer interfaced experiments was not possible within the budget constraints. For us, the optimal solution of the "equipment list and cost" problem was found in buying five sets The Projects in Optics Kit of Newport Corp. (\$5,230 each), one set of the state-of-the-art CA$1200 \mathrm{He}-\mathrm{Ne}$ laser from the German manufacturer MICOS Gmbh $(\$ 19,957)$, and one Modern Interferometry Kit from TEACHSPIN Inc. (\$12,000). The Newport kits include 3’x3' optical breadboards and all standard components required for the lab projects described in the Newport's Projects in Optics Workbook - lasers, power supplies, optical elements, holders, etc. As a matter of fact, these kits prove to be less expensive than buying individual components. We also purchased individual elements, such as PM 100 power meters and motion controlled stages (continuous rotation stages and XYZ-translation stages) from Thorlabs Inc. $(\$ 14,519)$, safety goggles, prisms, retroreflectors, half-wave plates, consumables (in multiple of four). We are currently evaluating the specifications of each component or system to determine how it would work for the proposed experiments. This equipment will satisfy our immediate needs, but to be able to offer various projects for undergraduate research we would also like to buy light emitting diodes (LEDs) with different wavelengths, an optical chopper, optical filters, an Abbe refractometer, a Schlieren system, photorefractive crystals and holographic plates, beam splitters, optical fibers and fiber couplings. After evaluating the success of our first semester, we intend to write a National Science Foundation (NSF) project requesting additional funds for enriching the current optics lab and possibly offering an advance course in optics.

\section{Evaluation}

\subsection{Assessment of student's learning}

Student's learning and progress will be assessed on a continuous base through the entire course. The continuous screening will involve class and group discussions on thought-provoking questions, as the emphases will be on student's misconceptions and experimental missteps. The student's preparedness and performance will be reviewed, and the lab report for each lab experiment will be graded on the basis of meaningful quantitative data, as well as qualitative interpretations. Three (two midterms and a final) exams are scheduled for the lecture material. The exams will include also questions on the laboratory experiments in order to assess the student's understanding of the lab procedures and data analysis. The student's individual work and self learning will be assessed via the student's individual projects and PowerPoint ${ }^{\circledR}$ presentations. The presentations will be evaluated based on content, oral delivery, visual aids, and relevance.

\subsection{Course evaluation}

At the end of the course, students will complete a questionnaire on various aspects of the course. Students will evaluate their background preparedness for the course, qualitative lap of knowledge, preliminary competency in lab techniques, the effectiveness of the lab experiments and projects, what lab experiments meet the course objectives, the effectiveness of the instructor's guidance, what should be improved in the lecture and lab portions of the course. The constructive students' suggestions will be the base for changes and improvement of the course. The interest shown by students will be the prime motivation for the frequency of course offering, as well as for developing a more specialized advanced course in optics.

\section{The impact of the Optics course}

\subsection{Undergraduate Research and Training in Optics}

We expect that the new optics course will impact strongly the department's advanced lab, undergraduate research and training program. A few research projects in optics were already offered to students for their twosemester senior seminar courses, PHYS 492 and PHYS 498, which are required for graduation for all physics majors. We plan to incorporate the optics teaching laboratory into the PHYS 451 and 452 advanced laboratories and the department's undergraduate research. Possible research projects may include optical sensors based on the surface plasmon resonance technique, studying the nonlinear optical properties of materials using the $z$-scan method, measuring small angles using Michelson interferometer, etc. Double majors, computer science \& 
physics or chemistry \& physics, may be offered optics undergraduate research projects that connect both disciplines. For example, computer science \& physics majors might be interested in the field of fiber optics, communications, holographic data storage, and pattern recognition. The chemistry \& physics majors will find their interests in spectroscopy, optical sensors, photoluminescence or optical properties of new materials synthesized in the Chemistry Department.

\subsection{The impact on the other departments through the School of Mathematics and Science}

We believe that the new course will inspire new projects and, possibly, new opportunities for collaborations. It is expected that the course will have a positive impact on other programs, like Chemistry, Biology, Earth Sciences, where sufficiently prepared students can benefit from learning about optical equipment and optical methods for measurements and control that they can use in their graduate studies for characterization of new materials and bio-objects. This might also increase the interdisciplinary work and joint activities among the departments of the School of Mathematics and Science.

\subsection{The impact on the department's curriculum}

The newly developed optics laboratory is expected to stimulate the development of additional optics experiments, and possibly, an advanced optics laboratory course. An advanced optics course might include elements of nonlinear optics, ultrafast spectroscopy, and optical properties of nanostructures and characterization of nanodevices, as well as scanning probe microscopy, atomic force microscopy, photonic crystals, semiconductor lasers. A part of the advanced course will deal with detailed introduction to basic optical standards and international standardization aspects of optical engineering, and laser safety standards, which will provide insight to terminology, requirements, interfaces, test methods, and product safety, that apply to complete optical systems, devices or components. With an additional advanced optics course, the Department will be able to offer a new option in BA physics with optics. Therefore, the described efforts will provide new opportunities and enrichment of the already existing two cooperative programs between our Department and The Pennsylvania State University and University of Southern California.

\subsection{The impact on the community}

The optics course will provide the basic resources for both research and training in modern optics. It will promote learning, teaching and training of students, faculty and K-12 teachers. Based on our experience with the course in fall of 2007, I anticipate offering a summer training workshop for K-12 teachers in summer 2008.

Our current percentage of female physics majors is typically between 10 and 20 percent. Most of our female students are enrolled in the BS in Education (Physics) program. Since optics is one of the most demonstrable parts of physics, we believe that the new optics course in combination with the BSE option will attract more female students to the field of physics and physics education.

We plan to regularly host open house receptions for the campus community and students and teachers from the local high-schools. The guests will visit our optics laboratory and will have the opportunity to speak with instructors and students involved in the optics course and to hear by word of mouth their experiences and future plans.

\section{Conclusion}

A rigorous lab based course in applied optics has been developed at MU. The new course, PHYS 331, Introduction to Optics, will be introduced for the first time at MU in fall semester, 2007. This course is required for BS physics majors, but will be open also to all majors from the School of Mathematics and Science, who have met the prerequisite requirements. Enrollment is restricted only by prerequisites and lab equipment limitations. The primary goal of the course is to provide students with the theoretical background and hands-on experiences necessary to enable them to successfully apply optics in their respective majors. Students learn the fundamentals of applied optics through a sequence of hands-on laboratory experiments using state-of-the-art equipment and multidisciplinary individual projects. Because of the hands-on experience requirement the enrollment is limited to maximum 12 students per semester. Initially, the optics course will be offered annually, and the interest shown by students will determine the frequency of its future offering. Adapting our educational efforts to the future challenges of our students, college education and training in optics becomes a high priority topic for the Physics Department at MU. 


\section{Acknowledgments}

I acknowledge the input of Dr. Tariq Gilani during the development of this course, as well as the support of the Chair and the members of the Physics Department. I thank also Dr. E. Shane, the Dean of the MU School of Mathematics and Science, for his encouragement and the financing of this project.

\section{References}

[1] R. Barat, J. Federici, A. Johnson, H. Gebel, and T. Chang, "Optical Science and Engineering Curriculum at NJIT,” Journal of Engineering Education, 575-582, (1998 Supplement).

[2] New Jersey Institute of Technology, Optical Science and Engineering (OPSE) Program, http://www.njit.edu/v2/Directory/Centers/OPSE/Welcome.html

[3] O. F. Swenson, D. A. Rogers, R. M. Patterson, A. Campiglia, “Optics for scientists and engineers," $32^{\text {nd }}$, ASEE/IEEE Frontiers in Education Conference, November 2-9, 2002, Boston, MA, IEEE Proc., S4A8-A12 (2002)

[4] F. Zhou, "Electro-Optics Program at Indiana University of Pennsylvania”, ETOP 2005, pp. 121-126/416.

[5] Martin Nemko, "How to Get an Ivy League Education at a State University", Avon Books (1988).

[6] A. M. Odlyzko, "Internet traffic growth: Sources and implications," Proc. ITCOM, SPIE (2003). E-version at http://www.dtc.umn.edu/ odlyzko/doc/itcom.internet.growth.pdf

[7] Some of the experiments are described on the MU Physics Department's website at http://muweb.millersville.edu/ physics/

[8] J. Ringlein, “Secondary Teacher Interacting with Materials Professors Strikes Gold”, MRS Bulletin 32, 179 (2007).

[9] F. L. Pedrotti, L. S. Pedrotti, L. M. Pedrotti, Introduction to Optics, 3d ed., Pearson Education, (2007).

[10] D. C. O'Shea, W. R. Callen, W. T. Rhodes, Introduction to Lasers and their Applications, $2^{\text {nd }}$ ed., Addison Wesley (1978).

[11] O’Svelto, "Principle of Lasers", Plenum Press (1998).

[12] D. C. O’Shea, “The Elements of Modern Optical Design”, J. Wiley and Sons, New York (1985).

[13] K. D. Moller, “Optics”, University Science Books, Mill Valley, CA (1988).

[14] Projects in Optics Workbook, Newport Corp. 